PublisherName : Springer International Publishing

PublisherLocation : Cham

Publisherl mprintName : Springer

\title{
Successive Interference Cancellation for DS-CDMA Systems with Transmit Diversity
}

\begin{tabular}{|c|c|}
\hline \multicolumn{2}{|r|}{ Articlel nfo } \\
\hline ArticlelD & : 1122 \\
\hline ArticleDOI & : 10.1155/S1687147204404022 \\
\hline ArticleCitationID & : 876317 \\
\hline ArticleSequenceNumber & : 18 \\
\hline ArticleCategory & : Research Article \\
\hline ArticleCollection & $\begin{array}{l}\text { : Innovative Signal Transmission and Detection Techniques for Next Generation } \\
\text { Cellular CDMA Systems }\end{array}$ \\
\hline ArticleFirstPage & $: 1$ \\
\hline ArticleLastPage & $: 2$ \\
\hline \multirow[t]{4}{*}{ ArticleHistory } & : RegistrationDate : 2003-10-30 \\
\hline & : 2003-10-30 \\
\hline & $2004-2-29$ \\
\hline & OnlineDate \\
\hline ArticleCopyright & $\begin{array}{l}\text { : Li and Gulliver } 2004 \\
\text { This article is published under license to BioMed Central Ltd. This is an open } \\
\text { access article distributed under the Creative Commons Attribution License, } \\
\text { which permits unrestricted use, distribution, and reproduction in any medium, } \\
\text { provided the original work is properly cited. }\end{array}$ \\
\hline ArticleGrants & : \\
\hline ArticleContext & : 136382004200411 \\
\hline
\end{tabular}


Wei Li, Aff1

Corresponding Affiliation: Aff1

Email: wli@ece.uvic.ca

T Aaron Gulliver, Aff1

Email: agullive@ece.uvic.ca

Aff1 Department of Electrical and Computer Engineering, University of Victoria, P.O. Box 3055 STN CSC, Victoria, BC V8W 3P6, Canada

\section{Abstract}

We introduce a new successive interference cancellation (SIC) technique for direct sequence code division multiple access (DS-CDMA) systems with transmit diversity. The transmit diversity is achieved with a space-time block code (STBC). In our work we first consider hard decision SIC with an STBC, and then investigate the performance of soft decision SIC with an STBC. System performance over a Rayleigh fading channel is investigated and the analysis is confirmed by simulation.

Keywords

multiuser detection, space-time codes, CDMA, SIC 